\title{
Spatial analysis of water stress and application of water poverty index in the Mahakali River Basin, Sudurpaschim Province, Nepal
}

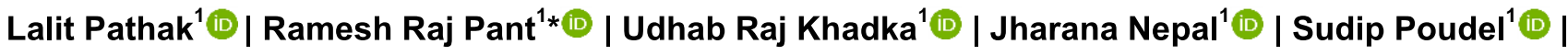

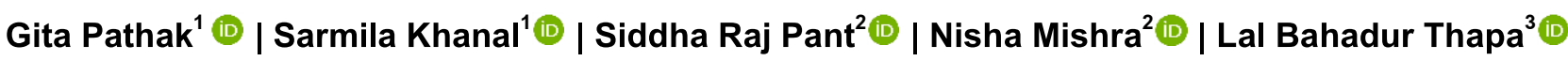 \\ ${ }^{1}$ Central Department of Environmental Science, Institute of Science and Technology, Tribhuvan University, Kathmandu, Nepal \\ ${ }^{2}$ Kailali Multiple Campus, Dhangadhi, Kailali Nepal \\ ${ }^{3}$ Central Department of Botany, Institute of Science and Technology, Tribhuvan University, Nepal \\ *Correspondence: rpant@cdes.edu.np
}

Received: 15 September 2020 | Revised: 18 November 2020 | Accepted: 20 November 2020

\begin{abstract}
Water Poverty Index (WPI) is an effective tool to assess water stress by linking physical approximations of water availability with socioeconomic drivers of poverty at household and community levels. It also helps in determining the priority needs for interventions and makes the better use of water resources without compromising the environmental integrity at the policy level. This study presents a comparative analysis of WPI to assess the water stress in two local units i.e., Mahakali Municipality-4 (Upstream) and Bhimdatt Municipality-13 (Downstream) of the Darchula and Kanchanpur districts, respectively along the Mahakali River Basin (MRB), Sudurpaschim Province, Nepal. Five components, i.e., resource availability, use of resources, capacity to utilize water sources, accessibility to water sources, and environment were applied to appraisal the water poverty. Under these components, 28 indicators were selected to visualize the water poverty condition. The information for acquiring these indicators was collected by making the field visit, semi-structured questionnaire survey, and secondary information from relevant sources. The results showed that the downstream segment has a higher WPI value (65.43) in comparison to the upstream segment (52.60) of the MRB, indicating relatively water-advantaged and stressed situations in down- and upstreams, respectively. Interestingly, despite having higher resource availability, the upstream region exhibited more stressed situations reflecting spatial heterogeneity in terms of capacity, environmental conditions, and infrastructure development to use the available water resources. Thus, in order to reduce the water stress conditions, priorities for intervention must be given to the water use capacity, especially in the upstream segment of the MRB. This study could be useful for academia and policymakers for the sustainable use of water resources in the MRB, Susurpaschim Province, Nepal.
\end{abstract}

Keywords: Mahakali River Basin, Resource availability, Resource utilization, Water poverty index, Water resources

\section{1 | Introduction}

Freshwater is a basic and critical resource to support ecosystem sustainability, human activities, and socioeconomic development of a country. It is well known that water provision and poverty alleviation have an inevitable connection with the communities, though the causes of poverty and their relation to water are very complex (Harrington et al. 2009). The various efforts are made to ensure water quality, availability, and accessibility for its justifiable utilization and livelihood improvements (Ogunbode \& Ifabiyi 2017). During the past few decades, both natural factors and anthropic activities threatening the freshwater resources of the world causing water scarcity. These threats are closely linked to water access and the capacity to use it by the communities
(Wescoat et al. 2007). Global climate change, rapid urbanization, rampant development, pollution, and deforestation are some of the major threats associated with the availability of freshwater in the Himalaya (Diwakar \& Thakur 2012). Water scarcity is the current focus of researches, particularly in relation to growing concerns about the impacts of climate change and rapid population growth (Vorosmarty et al. 2000). Thus, the nexus between water resources and livelihood needs to be explored intensively.

There are several indices developed for accessing timely and accurate information about the availability and status of water. Among the indices, Water Poverty Index (WPI) is a holistic tool designed to contribute effective water management (Sullivan 
2003). It provides combined measures of water availability and access in a particular environment ( Ifabiyi 2017). The elementary advantage of the WPI is that it encapsulates different components and customizes influencing factors in a single number representing the whole picture and can be applied at regional, national, and community levels (Sullivan et al. 2003, Thakur et al. 2017). Moreover, the poor households often suffer from poor water facility, and this results in a significant loss of time and effort, especially for the women in developing countries like Nepal. The WPI mostly captures the entire range of issues related to water resources availability and their impacts on people's livelihoods and poverty. Therefore, it is widely applied to evaluate the water resource -livelihoods nexus (Vyver 2013).

The WPI provides the measure of water accessibility with its five components: resources $(R)$, access $(A)$, capacity $(C)$, use $(U)$, and environment (E) (Thakur et al. 2017). Moreover, WPI can be localized easily that overlooks the causal connection between the water situation and adaptive capacities on financial as well as institutional levels (Feitelson \& Chenoweth 2002, Panthi et al. 2018). Thus, resource, access, use, capacity, and environment need to be linked with the social aspects in order to address the issues associated with sustainable use of water resources in the river basin level. Therefore, the mixed approaches by linking the physical and social sciences could greatly contribute to address the pertinent issues associated with water accessibility-livelihoods nexus.

Though Nepal holds $2.27 \%$ of world freshwater resources, the water poverty topic at the planning level is a burning issue for the local, provincial, and federal governments. Additionally, the increased challenges related to water pollution, and scarcity of water under the context of climatic change are the additional threats, particularly in the Himalayan regions (HEMS 2015, Thakur et al. 2017). It has been revealed that $<62 \%$ of the Nepalese population has access to potable water and only $29.7 \%$ of the total agricultural land is irrigated, despite its enormous significance to the livelihoods of local people (CBS 2019, World Bank 2010). The poor water quality, increasing water demand, and inadequate supply, growing population, low economic growth rate, lack of capacity, and skilled manpower for efficient and effective water management are some of the reasons that lead to the increased water poverty in Nepal (Panthi et al. 2018). Additionally, water poverty prevails more over the rural mountain regions due to the rugged topography and lack of capacity for using and managing water resources like irrigation and drinking water of the local people (Thakur et al. 2017). It reflects the necessity to measure poverty-related to water in a quantitative way in order to solve the aforementioned problems and disparities.

Thus, this study was carried out to apply WPI as a tool to explore and visualize the water poverty conditions in two climatically, topographically, and socio-economically distinct up-and downstream segments of the Mahakali River Basin (MRB), Sudurpaschim Province, Nepal. The findings of this study will provide the baseline information to the researchers, policymakers, and other concerned stakeholders about the water poverty status in the MRB which could be a milestone to promote sustainable livelihoods of the people in the other parts of the globe.

\section{2 | Materials and methods}

\section{1 | Study area}

Mahakali Municipality (Upstream-Mid Hill) and Bhimdatt Municipality (Downstream-Terai) of Darchula and Kanchanpur districts, respectively in the MRB of Sudurpaschim Province, Nepal were considered for the study (Fig. 1). Mahakali Municipality is located between $29.45 \mathrm{~N}$ and $80.24 \mathrm{E}$, has a population of 21,231 with an area of $135.11 \mathrm{~km}^{2}$. This municipality is surrounded by Naugad Rural Municipality in the east, Dharchula area of India in the west, Duhu Rural Municipality in the north and, Sailyasikhar Municipality and Malikarjun Rural Municipality in the south. With the rough topography of the elevation range $900-3100 \mathrm{~m}$., this area poses a cold temperate climate with an average annual rainfall of $2129 \mathrm{~mm}$.

Likewise, Bhimdatt Municipality is located between latitudes 28.86 and 28.97 North and longitudes 81.52 and 81.62 East with an elevation of $\sim 230 \mathrm{~m}$. This area falls under a tropical climate with an average annual rainfall of $1771.5 \mathrm{~mm}$. The total population of Bhimdatt Municipality is 104,599 with an area of $171.80 \mathrm{~km}^{2}$. It is surrounded by Bedkot Municipality in the east, Mahakali Municipality in the west, Dadeldhura district, and India in the north, and Sukhlaphata National Park (SNP) in the south. Both of the municipalities are located along the bank of the Mahakali River and people's livelihood is directly affected by the water in the river. Owing to the fertile area, the upstream segments of this study have the great potential for agricultural production as in the downstream segment. 


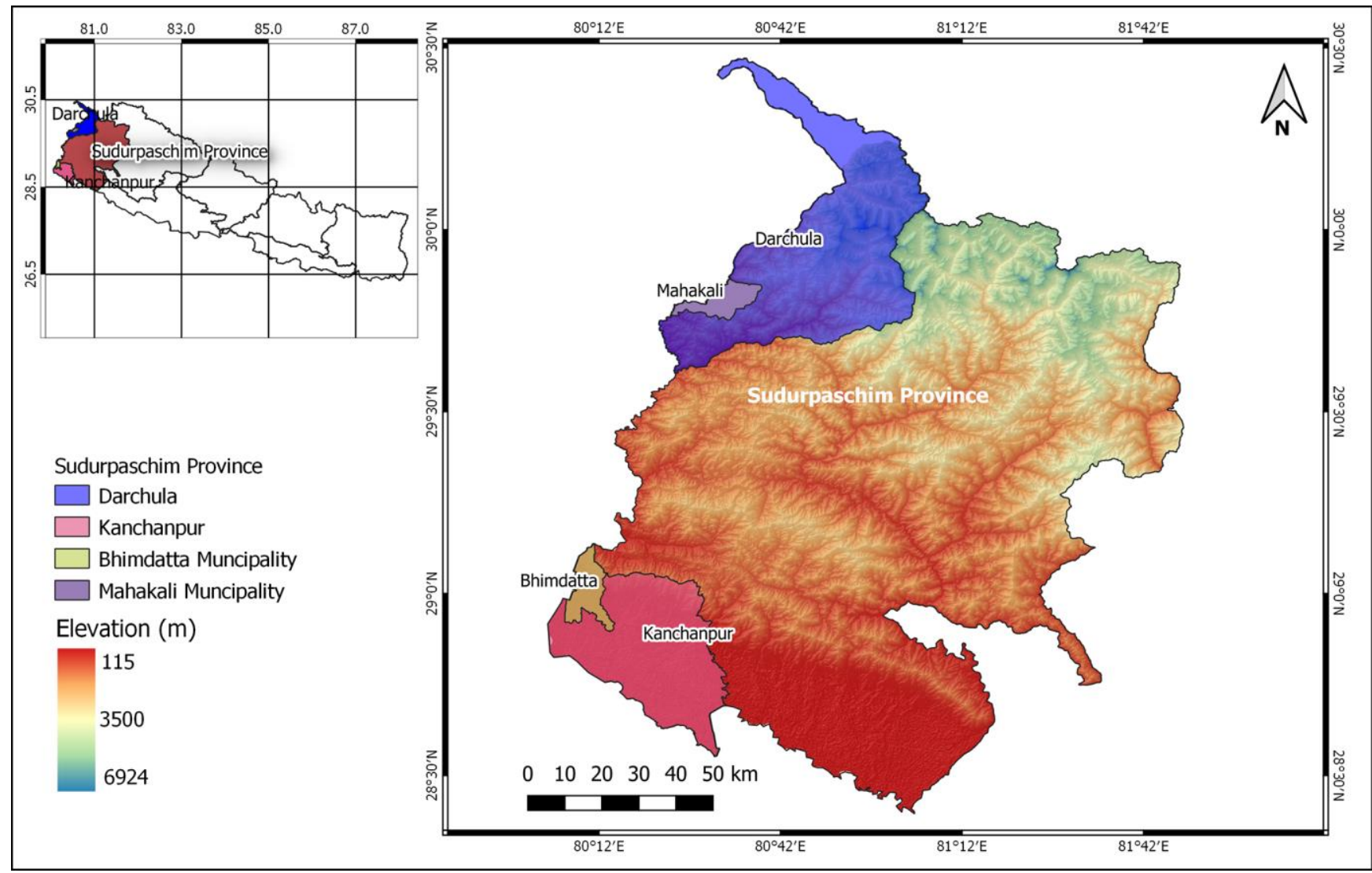

Figure 1. Bhimdatta (downstream) and Mahakali (upstream) Municipalities of Sudurpaschim Province, Nepal

\section{2 | Data collection and analysis}

In the study, both qualitative and quantitative techniques of data collection and analysis were applied. A semi-structured questionnaire was prepared to acquire the primary data at the household level. The sample size was determined by using the formula given by Cochran (1963) with a 95\% confidence level and a $10 \%$ margin of error. The study area was divided into different strata for the collection of representative data and stratified random sampling was done from each sub-stratum in October 2019. The household survey was conducted in one ward (local unit) from each upstream and downstream segment of the MRB for collecting information on water use, water carrying time, a household with livestock, and household size. A total of 87 households were selected out of 862 in Ward-13 of Bhimdatta Municipality in the downstream segment whereas 89 households out of 1162 in Ward- 4 of Mahakali Municipality in the upstream segment.

Four strata were made as a household having agricultural activities only, livestock only, agriculture and livestock both, and other economic activities. For the key informant interview (KII) including the local representatives (Municipality Mayor and Ward
Chairperson) of both wards, and government officers (CDO, Darchula) were consulted for this study. Likewise, secondary data such as land cover, meteorological, and census data were acquired from different government institutions like the Department of Hydrology and Meteorology (DHM), Central Bureau of Statistics (CBS), and district and municipality profiles.

\section{3 | WPI calculation}

Water Poverty Index (WPI) was calculated with the Composite Index Approach developed by (Sullivan et al. 2003) as follows;

$$
W P I=\frac{\mathrm{W}_{r} * \mathrm{R}+\mathrm{W}_{a} * \mathrm{~A}+\mathrm{W}_{u} * \mathrm{U}+\mathrm{W}_{u} * \mathrm{C}+\mathrm{W}_{e} * \mathrm{E}}{\mathrm{W}_{\mathrm{r}}+\mathrm{Wa}+\mathrm{Wu}+\mathrm{Wc}+\mathrm{W}_{e}}
$$

Where, $\mathrm{Wr}, \mathrm{Wa}, \mathrm{W}_{\mathrm{c}}, \mathrm{Wu}$ and $\mathrm{We}$ are the weighted average of five components as resources $(R)$, access $(A)$, capacity $(C)$, use $(U)$, and environment $(E)$, respectively. Each of these components was first standardized to get the value within the range of 0 to 100. Thus, the resulting WPI value is between 0 and 100 where the zero indicates a water-stressed situation while 100 shows a water-advantaged situation. 


\section{Indicators used}

The indicators of the components in this study have been slightly modified from Sullivan et al. (2006) and Ogunbode and Ifabiyi (2017). Resources (R), access (A), capacity (C), use (U), and environment $(E)$ indicated the physical availability of surface water resources; provision of water supply and sanitation services to the people; capacity of society to harvest resources; water use by different sectors and environmental significance of water resources and its capacity to provide environmental services, respectively (Table 1). As the study was carried out in two distinct geographical areas, the indicators used were selected on the basis of their comparative utility.

Table 1. Different indicators used in five components of WPI in the study area

\begin{tabular}{|c|c|}
\hline Components & Indicators \\
\hline Resource (R) & $\begin{array}{l}\text { - Runoff potential } \\
\text { - Rain potential } \\
\text { - Current runoff } \\
\text { - Sufficient perennial runoff } \\
\text { - Perennial benefit factor }\end{array}$ \\
\hline Access (A) & $\begin{array}{l}\text { - The household that depends on the distance water source } \\
\text { - Percent of the household having conflict at the water point } \\
\text { - Percent of water carried by women } \\
\text { - Access to sanitation (access to toilet facility) } \\
\text { - The household that depends on pipe water sources } \\
\text { - Reliability of pipe water supply } \\
\text { - Time taken to fetch water (both ways + storing) from the } \\
\text { source for distant water Supply }\end{array}$ \\
\hline Capacity (C) & $\begin{array}{l}\text { - Land ownership with size } \\
\text { - Total arable land }(\mathrm{km} 2) \\
\text { - Total area access to irrigation } \\
\text { - Literacy rate } \\
\text { - Number of households with economic activities } \\
\text { - The mortality rate of children under five years }\end{array}$ \\
\hline Use (U) & $\begin{array}{l}\text { - Household size } \\
\text { - Assumed minimum water requirement } \\
\text { - Optimum water requirement } \\
\text { - Household having agriculture land plus livestock } \\
\text { - Households having only agricultural land } \\
\text { - Daily water collection for households having agricultural } \\
\text { land plus livestock } \\
\text { - Daily water collection for households having only } \\
\text { agricultural land }\end{array}$ \\
\hline Environment (E) & $\begin{array}{l}\text { - Report on crop loss over the last } 5 \text { years } \\
\text { - Percent of a household affected by flood ( } 5 \text { years) } \\
\text { - } \% \text { of the area with natural vegetation }\end{array}$ \\
\hline
\end{tabular}

\section{Calculation of the components}

The calculation of each component was completed using a weighted indicator. The calculation process is described below on the basis of Sullivan (2002) and Thakur et al. (2017).

\section{a) Resource (R)}

The resource $(R)$ is calculated as

$$
R=\frac{I r+I k}{2} \times 20
$$

where, $\mathrm{I}_{\mathrm{R}}=$ Rainfall index; $\mathrm{I}_{\mathrm{K}}=$ Runoff index

If annual rainfall produces a surplus over water requirement for annual crop rotation in the area, the rain source is surplus, i.e. rain index $\left(I_{R}\right)=1$. If rainfall is ' $p$ ' percent less than the annual crop water requirement, the rain sub-index $\left(I_{R}\right)$ rating is $=1-(p / 100)$.

Runoff index is calculated by using the following calculation based on USDA (1986), which is well suited for small scale studies as it requires less effort with soil type, land use, and vegetation coverage (Ponce and Hawkins 1996; Sharma 2001). The model as mentioned is suitable for clay, loam, and sandy clay soils from plane to gentle slope areas with mixed vegetation coverage which is quite suitable for our study.

$Q=0.48(P-635)$

Runoff Index $=Q / P$

where, $Q=$ Runoff; $P=$ Precipitation

\section{b) Access (A)}

The Access $(A)$ was calculated as:

$$
A=\frac{I d+I s}{2} \times 20
$$

where, $I_{d}$ and $I_{S}$ are the household water carrying time index and irrigation access index, respectively.

Water carrying time index (Id) is:

$$
I d=1-\frac{T}{T \max }
$$

where, $\mathrm{T}$ is the time needed to collect and store water, the $T_{\max }$ is the maximum time required for water collection and storage. For the household with a direct pipe supply in the house, the value of $T$ is 0 .

Sanitation access index (Is) was calculated as:

$$
I s=\frac{S i}{S a}
$$

where, $\mathrm{Si}=$ total household with access to a sanitation facility; $\mathrm{Sa}=$ total household in percent.

c) Capacity (C)

$$
C=\frac{I c+I i c+I t}{3} \times 20
$$


where, Ic = education capacity index; lic = income capacity index; It $=$ irrigation water index .

Also,

Education capacity index $=\mathrm{L} / 100$

Income capacity index $=\mathrm{Te} / \mathrm{Th}$

Irrigation water index $=\mathrm{Ha} / \mathrm{Ht}$

where, $\mathrm{L}=$ literacy rate; $\mathrm{Te}=$ household involved in economic activities; $\mathrm{Th}=$ total household; $\mathrm{Ha}=$ total land with irrigation; $\mathrm{Ht}$ $=$ total agricultural land.

d) Use (U)

The Use $(U)$ depends on the water need for a household in liters/capita/day (Icd). It can be calculated as:

$$
U=\frac{S-S \min }{S-S \min } \times 20
$$

where, $S=$ Total water used by households $(\mathrm{l} / \mathrm{c} / \mathrm{d})$; Smin = minimum water requirement $(\mathrm{l} / \mathrm{c} / \mathrm{d}) ; \mathrm{Smax}=$ maximum water needed in a household $(\mathrm{I} / \mathrm{c} / \mathrm{d})$.

Again,

$$
S=\frac{K}{H e}
$$

where, $\mathrm{He}=$ Household Size; and $\mathrm{K}$ is calculated as,

$$
K=\frac{L a * H a+L b * H b}{H t}
$$

where, $\mathrm{La}=$ daily water collection in liters for households; $\mathrm{Ha}=$ households having only agricultural land; $L b=$ the daily water collection in liters for households; $\mathrm{Hb}=$ households having agricultural land plus livestock; $\mathrm{Ht}=$ the total number of households.

The household with only agricultural land utilizes 200 liters of water per household and the household with both agricultural land and livestock utilizes 300 liters of water per household. The optimum water requirement is assumed to be $160 \mathrm{l} / \mathrm{c} / \mathrm{d}$ and the minimum water requirement is assumed to be $1 \mathrm{l} / \mathrm{c} / \mathrm{d}$ (Thakur et al. 2017).

\section{e) Environment ( $E$ )}

Environment $(E)$ is calculated on the basis of crop loss, flood effect on households, and vegetation index and it is calculated $\mathrm{s}$ :

$$
E=\frac{C l+I v}{2} \times 20
$$

where, $\mathrm{Cl}=$ Cumulative of crop loss and flood impact; IV $=$ Vegetation index respectively.

Then,

$$
\text { Iv }=\frac{V}{A}
$$

where, $\mathrm{V}=$ natural vegetation coverage area; $\mathrm{A}=$ total area.

\section{Water poverty intensity scale}

\begin{tabular}{|c|c|}
\hline WPI intensity scale & Category \\
\hline $75-85$ & Very low \\
\hline $65-75$ & Low \\
\hline $55-65$ & Medium-low \\
\hline $45-55$ & Medium \\
\hline $35-45$ & Medium-high \\
\hline $25-35$ & High \\
\hline $15-25$ & Very high \\
\hline
\end{tabular}

The water poverty intensity scale is ranged from 0 to 100 . The benchmark of maximum 85 and minimum 15 is considered (Bonan et al. 2003). The Water Poverty Intensity scale is shown in Table 2.

The value above 100 or below zero is adjusted between 100 and 0 , with 75 as very low and 25 as very high WPI.

\section{3 | Results}

\section{1 | WPI and its components}

The average WPI score in the MRB was found to be (59.01). The water poverty index for the downstream segment (Bhimdatta Municipality-13) in the Tarai region of Kanchanpur district was higher (65.43) as compared to the upstream segment (52.6) of the Mahakali Municipality-4 in Mid-hill of Darchula district (Table 3). The major components of WPI for downstream segment can be listed in descending order as: capacity > use > access > environment > resources, whereas in the upstream segment: resource $>$ access $>$ use $>$ capacity $>$ environment (Table 3 ). Looking at the similar component between two distinct geographic locations, the resource component is found to be higher in the upstream segment than of the downstream segment in this study. Besides that, the other components such as access, capacity,

Table 1. WPI score for each component in the study area

\begin{tabular}{|l|c|c|c|c|c|c|}
\hline \multicolumn{1}{|c|}{ Region } & Resource & Access & Capacity & Use & Environment & WPI \\
\hline Downstream & 10.00 & 12.43 & 17.00 & 15.00 & 11.00 & 65.43 \\
\hline Upstream & 12.00 & 11.67 & 9.60 & 10.00 & 9.33 & 52.60 \\
\hline
\end{tabular}

use, and environment are higher in the downstream segment.

\section{2 | Contributing factors for different WPI}

The indicators used were found to be affected by different topographic and socioeconomic factors in the study area. The resource component mainly includes the precipitation amount, 
runoff coefficient, and nature of the nearby river which is higher (12) in upstream than that of the downstream segment (10) as presented in Fig. 2. Access depends upon sanitation index which was calculated by using total household with access to sanitation facility and water carrying time index. So, this ensures better access to safe drinking water for good health and sanitation. The access in the downstream segment was found to be 12.43 , whereas in the upstream segment was 11.67 (Table 3 ). This

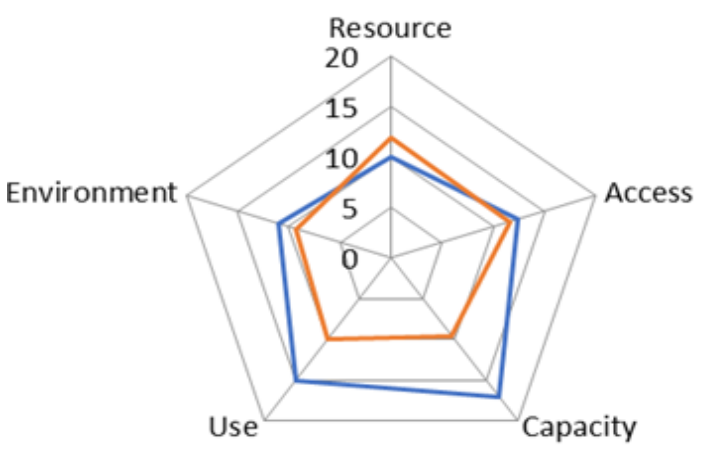

$\underline{\text { Overall WPI }}$

Downstream segment $=65.43$

Upstream segment $=52.60$

Figure 2. Components of the final Water Poverty Index (WPI) illustrating the score for each component of both up-and downstream segments of the Mahakali River Basin (MRB), Nepal

difference is caused due to higher sanitation facility i.e., toilets with water access in the households in Bhimdatta Municipality and less sanitation access in Mahakali Municipality. A large gap was found between a capacity component in the study area, i.e., downstream segment (17) and upstream segment (9.6) (Table 3) by a higher number of households in the downstream region (Bhimdatta Municipality) involved in the economic activities. The use component integrates all the indicators like household size, water collection by households, and water requirements that influence the use of existing resources with their capacity. In the present study, the capacity of the downstream segment (Bhimdatta Municipality) was found to be 15 , whereas that of the upstream segment (Mahakali Municipality) was 10. The environmental component of the WPI incorporates cumulative crop loss and flood impact and vegetation coverage. The environmental capacity in the downstream segment (Bhimdatta Municipality) was found to be 11 , whereas it was 9.33 in the upstream segment.

\section{4 | Discussion}

\section{1 | WPI and its components}

The overall WPI of Nepal is 54.4 having each component 10.2 $8.7,11.2,12.6$, and 11.8 for resource, access, capacity, use, and environment, respectively (Lawrence et al. 2002). In this study, it was found that the downstream segment has a higher value of WPI than that of the national average index, whereas lower in the upstream segment. The higher value of the water poverty index signifies the water advantaged situation and vice versa. This indicated the situation of water scarcity comparatively higher in the upstream segment, which is mainly caused due to lower use and capacity of the people to over the existing resources. The scale of WPI intensity, poverty situation of the downstream region falls under low poverty, whereas the upstream falls in the medium poverty category and the similar results were also obtained in the study of WPI in Karnali River Basin (Panthi et al. 2018).

Most of the respondents in the upstream segment of the MRB believe that the river is only for boundary purposes, and limited applications of the river water to their livelihoods, which could be due to lack of irrigation infrastructures. However, the key informants believe that the use of water from the Mahakali river could help to increase productivity in the agriculture sector and enhance the livelihood of the local people in the future. In agreement with the respondents, it is anticipated that the increase in the capacity component will enhance the livelihoods as the total arable land in the upstream region is $74 \%$ of total land and only $12 \%$ have irrigation facilities to date (DP 2017). Whereas in the downstream $93 \%$ of the land area is arable with $89 \%$ access for irrigation (DP 2017). Hence, the limited use of water for the agricultural sector contributes to water poverty in the upstream region. Similarly, access to water resources shows a better situation in the downstream segment as well. It reveals the improvement in the upstream segment mainly in terms of sanitation facilities like $95 \%$ and $82 \%$ of families have toilet facility in the downstream and upstream, respectively (DP 2017). Also, access to the piped water is only about $12 \%$ in the upstream region contributing to water poverty (DP 2017). In this way, WPI at the local scale delivers a clear view of the problems in different components related to the water-deprived situation. Different 
studies associated with WPI in Nepal and across the globe reflect the distinction with respect to socioeconomic, developmental, climatic, and topographic aspects (Komnenic et al. 2009, Koirala et al. 2019, Panthi et al. 2018). Generally developed areas were found to be water advantaged situation because of their proper utilization capacity though having lesser resources and our results are also consistent with the same.

\section{2 | Contributing factors for different WPI}

The contributing factors of WPI were markedly distinct in the upand downstream segments of the Mahakali river. The reasons behind the difference in the WPI index in two different geographic areas is clearly described by the indicator used for the calculation of WPI. Runoff index which depends upon the amount of rainfall over the area is mainly responsible for higher values of resource component in the upstream segment. Resource availability directly affects the availability of the water resource and increases resilience as well as decreases the water poverty of the area (Manandhar et al. 2011, Sulliva 2001). The access in the upstream manifests the un-usability of the available resources and similar to results were also obtained from the prior studies in Nepal (Manandhar et al. 2011, Sullivan 2001). Precisely, the lesser access not only indicates the lack of piped water but also the distribution and reliability of the water for all the seasons in our study.

The significant difference in capacity indicates lower effectiveness of the people to utilize the water sources in the upstream segment as the total land with irrigation was relatively low. This directly affects the economic capacity that allows the purchase of improved water, access to technology, and resources to cope with water-related stress and social capacity that people become aware of water, sanitation, health, and environmental issues. These findings are consistent with the previous studies from the major river basins of Nepal (Table 4). Not only the utilization but the lack of irrigation infrastructures and modern technologies are responsible for the lower use of water in the upstream region. The previous studies conducted in the Karnali and the Koshi River Basins in Nepal also showed good agreement with the aforementioned

Table 3. WPI in different river basins of Nepal findings (Panthi et al. 2018, Koirala et al. 2019).

Besides this, the surrounding environment also influences the water poverty level and other social well beings as it provides the ecosystem services and goods to the people (Sullivan 2001). Different hazards and environmental phenomenon have impacts on the WPI, as the heavy flooding in 2013 , has caused the huge loss of lives and property in the upstream segment of the MRB, which lowers the environment component and therefore, increases water poverty level (Paudel et al. 2013).

Despite these different indicators used for the calculation of WPI, the topography is also one of the important factors to be considered, as it can make more problematic or relax for utilizing the available water resources (Panthi et al. 2019). In the present study, the water poverty in the upstream segment is higher due to some changeable (infrastructures, socioeconomic) and unchangeable (topographic and climatic) factors. Overall, forest coverage in the upstream region was more, but the incidence of flood events was observed in the region during the last five years that caused the loss of crop which aids in the increase in poverty. Proper intervention for disaster risk reduction and utilization of the existing water in a sustainable way can enhance environmental resiliency and reduce poverty.

The average WPI score (59.01) for the Mahakali Basin in Nepal can be considered medium-low in terms of water stress, and the results in this study are comparable to other existing studies conducted at watershed levels in other parts of the country (Table 4). WPI found to be varying along the up-and down-stream in all of the watershed and generally water poverty was found to be higher in upstream regions. The Bagmati River Basin was found to be the least water-stressed with an average WPI of 65.26 in comparison to others such as Koshi, Kaligandaki Karnali, and Mahakali River basins as shown in Table 4. Many tributaries in the upper part of the Bagmati River basin and high access to groundwater resource in the Kathmandu Valley decreases the water poverty, though having harsh environment component due to anthropic pollution (Thakur et al. 2017). Average WPI score in

\begin{tabular}{|l|l|l|l|l|l|l|l|}
\hline River & Resource & Access & Capacity & Use & Environment & WPI & References \\
\hline Mahakali Basin & 55 & 60.25 & 66.5 & 62.5 & 50.8 & 59.01 & This study \\
\hline Bagmati Basin & 77.3 & 90.4 & 56.5 & 57.3 & 44.8 & 65.26 & (Thakur et al. 2017) \\
\hline Koshi Basin & 40.05 & 70.28 & 56.36 & 66.78 & 62.64 & 59.22 & (Koirala et al. 2020) \\
\hline Kaligandaki Basin & 85 & 75.5 & 46.5 & 13.3 & 25.5 & 49.2 & (Manandhar et al. 2011) \\
\hline Karnali Basin & 73 & 46 & 46 & 30 & 40 & 47.67 & (Panthi et al. 2018) \\
\hline
\end{tabular}


the Karnali River basin was the least (47.67). There were mainly two causes behind this; the first one was climatic and environmental changes as some parts of the Karnali River basin (Kalikot) are highly vulnerable to drought and climate change (NAPA 2010). And the second one was a poor capacity to manage the available water resources in terms of developments of the infrastructures (Panthi et al. 2018).

In a study carried out in the Kali Gandaki River Basin, the average WPI value for the basin was found to be 49.20 which is less than the present study but the water resources are abundant with the highest resource component $(R=85)$ among the entire watershed compared in Table 4. It is found that though a massive patch of an area in the Kaligandaki River basin lies under the rain shadow area (7th and 10th highest mountains i.e., Dhaulagiri and Annapurna-8,137 and 8,168 masl), snow melting from the mountains continuously supply and maintain water resources in the basin (Manandhar et al. 2011). Additionally, the physical inconvenience of water resources availability caused the least water resources (40.05) in the Koshi River basin (Koirala et al. 2020), which was a similar type of observation to the present study.

The implementation of technologies like the reuse of water after treatment, rainwater harvesting, and other storage decreases the time required to carry water in urban areas. Also, the majority of the people $(80 \%)$ have water pipelines to their houses in the Bagmati River basin which increases their access to watermaking resource components (90.4) (Thakur et al. 2017). Higher agricultural land and irrigation facilities are in terms of increased agricultural output, better employment especially for resourcepoor farmers and landless, lower food prices, and better nutrition for good health and livelihoods (Saleth et al. 2003). This is reflected by higher use and capacity components in downstream of the Bagmati, Koshi, and Mahakali River basins. But the use of chemical fertilizer in cultivated areas suppressed the environment as an excessive amount of use has adverse effects on soil fertility and the effect on water quality is even more serious (Brown 1997). Environmental integrity in mountainous regions of Nepal (including Kaligandaki River basin with Environment component 25.5) found to be poor along with crop intensification and farmer's growing interest in cash crop production using chemical fertilizers (Manandhar et al. 2011).

The water poverty at different watershed using diverse indicators suitable for respective studies (Panthi et al. 2018, Manandhar et al. 2011, Thakur et al. 2017) for different components of WPI concluded that the upstream having the higher water poverty, similar to our study. But Koirala et al. (2020) discovered higher water stress in the Tarai region, compared to the high-hill and mid-hill region due to poor access to sanitation, high illiteracy rate, and low per capita income in Tarai districts in the Koshi River Basin. The lack of proper management of existing resources due to limited infrastructure and capacity (institutional and public) was one of the major problems in all of the river basins in Nepal Himalaya. Besides poor domestic water use, lack of water treatment, and weak irrigational use are mainly responsible for water poverty in these basins.

\subsection{Implication of WPI for the Mahakali River Basin}

The WPI is one of the widely used scientific tools for the evaluation of water resource status in the river basin. However, the indicators used in WPI may vary distinctly as one community cannot be best for describing the situation for another community. The physical environmental factors may also responsible for the variation of the WPI due to differences in its terrain, settlement patterns, and climatic conditions.

The result of this study implies the different needs of water resource planning, management, and research in up-and downstream segments that are topographically, socioeconomically, and climatically distinct to each other. The results revealed that appropriate attention should be given in the upstream segment mainly focusing on enhancing the environment and capacity component. This can be done by reducing the risk of environmental hazards, for instance, construction of flood resilient infrastructures, gabion walls for protection in the bank of the Mahakali River. The other important point is that there is an urgent need for an adequate supply of safe drinking water and sanitation facilities. Similarly, in the downstream segment, the priority should be given to the resource and environmental component. This result could be useful for the local, provincial, and federal governmental bodies, and other concerned stakeholders to prioritize their efforts in reducing the water stress and planning for sustainable developmental activities.

\section{5 | Conclusions}

This study came up with a set of water poverty indicators to evaluate the water poverty situation in the topographically, climatically, and socio-economically distinct upstream and 
downstream segments of the Mahakali River Basin (MRB), Sudurpaschim Province, Nepal. It revealed that the Water Poverty Index (WPI) varies from 52.60 (in the upstream segment) to 65.43 (in the downstream segment) in the MRB, and displays that despite the higher availability of the resources, there is poor water use and environmental integrity. Furthermore, the results undoubtedly specify inappropriate management of water resources in the basin and suggest the need for location and problem-specific programs and policy interventions, and sustainable planning to improve the water poverty situation across the river basin.

Specifically, analysis of the WPI components in the up-and downstream segments showed great variations in water resources use and capacity than access, suggesting the areas of improvement needed in the overall river basin. Moreover, water poverty is much higher in upstream (Mahakali Municipality) due to the lack of capacity of the community to use the resources. This evidently indicates that the upstream segment should get the priority followed by the downstream segment to develop its capacity to use the existing resources, and environmental integrity. The development of sanitation facilities and economic activities are immediate requirements to reduce water poverty in the upstream segment. The water poverty in the upstream can be improved by higher coverage of water supply and increasing its reliability, whereas, in the downstream region, access, sanitation, urban management and increase in forest coverage could help to reduce water poverty.

This study depicts that priorities could different in order to reduce water poverty if the geography and other environmental setting are distinct. Therefore, policies should focus on strengthening water management plans for the efficient use of available water resources. In addition, further in-depth research by adopting a mixed approach with a larger sample size could give new insights on water poverty status in the glacier-fed Himalayan river basins

\section{Acknowledgements}

The authors would like to thank the University Grants Commission (UGC), Nepal for the financial support (Award No.: FRG-75/76-S \& $T-10)$ of this work. The authors are grateful to the Central Department of Environmental Science; IoST-TU; Kailali Multiple Campus, Dhangadhi and all the local people who directly and indirectly suppoted for this research work.

\section{Authors' contributions}

Pathak, L. collected the necessary data, analyzed and prepared the manuscript; Pant, R. R., Khadka, U., Thapa L. B., and Pant S. R. conceptualized the study and contributed critically in finalizing the draft manuscritp; Nepal, J., Poudel, S., Pathak, G., Khanal, S. and Mishra, N. assisted during the data collection and performed GIS analysis.

\section{Conflicts of interest}

Authors declare no conflict of interest.

\section{ORCID}

Lalit Pathak (D) https://orcid.org/0000-0003-0335-6398

Ramesh Raj Pant (D) https://orcid.org/0000-0002-6170-0188 Udhab Raj Khadka (D) https://orcid.org/0000-0003-0009-7263 Jharana Nepal (D) https://orcid.org/0000-0003-0317-4375 Sudip Poudel (iD https://orcid.org/0000-0002-7491-5129 Gita Pathak (D) https://orcid.org/0000-0002-1844-3550 Sarmila Khanal (D) https://orcid.org/0000-0002-1204-994X Siddha Raj Pant (D) https://orcid.org/0000-0002-7856-2914 Nisha Mishra (D) https://orcid.org/0000-0002-5549-8331 Lal B Thapa (D) https://orcid.org/0000-0003-3513-2276

\section{References}

Bonan, G. B., Levis, S., Sitch, S., Vertenstein, M. and Oleson, K. W. 2003. A dynamic global vegetation model for use with climate models: concepts and description of simulated vegetation dynamics. Global Change Biology 9(11):1543-1566. https://doi.org/10.1046/j.1365-2486.2003.00681.x

Brown, S. J. 1997. Soil fertility, nutrient dynamics and socio-economic interactions in the middle mountains of Nepal (Unpublished master's thesis). The University of British Columbia, Canada.

Cochran, W. G. 1963. Sampling techniques $\left(2^{\text {nd }}\right.$ ed). John Wiley and Sons Inc, New York, p 413.

Diwakar, J. and Thakur, J. 2012. Environmental system analysis for river pollution control. Water Air Soil Pollution. 223(6):3207-3218. https://doi.org/10.1007/s11270-012-1102-z

District Profile. 2017. Local Level Profile : Darchula District. Statistics office, Darchula, Nepal.

District Profile. 2017. Local Level Profile: Kanchanpur District. Statistics Office, Kanchanpur, Nepal.

Feitelson, E. and Chenoweth, J. 2002. Water poverty: towards a meaningful indicator. Water Policy 4(3):263-281. https://doi.org/10.1016/S1366-7017(02)00029-6

GoN/CBS. 2019. Environmetntal Statistics of Nepal 2019. Retrieved 27 January 2020 from https://nepalindata.com/media/resources/items/13/b.Environment-Statistics-of-Nepal-2019.pdf .

Harrington, L. W., Huber-Lee, A. and Vidal, A. 2009. Agricultural water productivity and poverty: a conceptual pathway to link global, basin 
and local understanding. Irrigation and Drainage 58(S1):S60-S72. https://doi.org/10.1002/ird.485

HEMS. 2015. LUPWY Documentation. Developer Manual. Health and Environmental Management Society (HEMS), Kathmandu, Nepal. Koirala, S. Fang, Y., Dahal, N. M., Zhang, C., Pandey, B. and Shrestha, S. 2020. Application of Water Poverty Index (WPI) in Spatial Analysis of Water Stress in Koshi River Basin Nepal, Sustainability 12(2):727. https://doi.org/10.3390/su12020727

Komnenic, V., Ahlers, R., and Van Der Zaag, P. 2009. Assessing the usefulness of the water poverty index by applying it to a special case: Can one be water poor with high levels of access?. Physics and Chemistry of the Earth 34(4-5):219-224.

https://doi.org/10.1016/j.pce.2008.03.005

Lawrence, P., Meigh, J., and Sullivan, C. 2002. The water poverty index: An international comparision. Straffordshire, UK: Department of Economics, Keele University, p 24.

Manandhar, S., Pandey, V. P., and Kazama, F. 2011. Application of Water Poverty Index (WPI) in Nepalese context: A case study of Kali Gandaki River Basin (KGRB). Water Resource Management Volume 89:107. https://doi.org/10.1007/s11269-011-9907-x

NAPA 2010. National Adaptation Programme of Action (NAPA). Kathmandu: Ministry of Environment, p 77.

Ogunbode, T. and Ifabiyi, I. 2017. Application of Water Poverty Index (WPI) in Assessing Water Accessibility in the Rural Suburbs of Ogbomoso Zone of Oyo State, Nigeria. Asian Journal of Environment and Ecology 3(2):1-9. https://doi.org/10.9734/AJEE/2017/34095

Pandey, V. P., Manandhar, S. and Kazama, F. 2012. Water Poverty Situation of Medium-sized River Basins in Nepal. Water Resources Management 26(9):2475-2489.

https://doi.org/10.1007/s11269-012-0027-z

Panthi, J., Khatiwada, K., Shrestha, M. L. and Dahal, P. 2018. Water Poverty In Context of Climate Change: A case study from Karnali River Basin in Nepal Himalaya. International Journal of River Basin Management 17(2):243-250. https://doi.org/10.1080/15715124.2018.1531421

Paudel, P., Regmee, S. B. and Upadhyay, S. N. 2013. Overview of June 2013 Flood and Landslides with focus on Darchula Disaster. Hydro Nepal 13:57-63.

Pons, V. M. and Hawkins R. H. 1996 Runoff curve number: has it reached maturity? Journal of Hydrology Engineering 1:11-19.

Saleth, R. M, Samad, M., Molden, D. and Hussain, I. 2003, Water, poverty and gender: an overview of issues and policies. Water Policy 5:385-398. https://doi.org/10.2166/wp.2003.0024

Sharma ,T., Satya Kiran, P. V., Singh, T. P., Trivedi, A. V. and Navalgund, R. R. 2001, Hydrological response of watershed to landuse changes: Remote sensing and GIS approach. International Journal of Remote Sensing 22:2095-2108

Sullivan, C. 2001. The potential for calculating a meaningful water poverty index. Water International 26(4):471-480. https://doi.org/10.1080/02508060108686948
Sullivan, C. 2002. Calculating a water poverty index. World development 30(7):1195-1210. https://doi.org/10.1016/S0305-750X(02)00035-9

Sullivan, C. A., Meigh, J. R., Giacomello, A. M., Fediw, T., Lawrence, P., Samad, M. et al. 2003. The water poverty index: Development and application at the community scale. Natural Resources Forum 27(3):189-199. https://doi.org/10.1111/1477-8947.00054

Sullivan, C., Meigh, J. and Lawrence, P. 2006. Application of the Water Poverty Index at Different Scales: A Cautionary Tale: In memory of Jeremy Meigh who gave his life's work to the improvement of people's lives. Water International 31(3):412-426. https://doi.org/10.1080/02508060608691942

Thakur, J. K., Neupane, M. and Mohanan, A. A. 2017. Water poverty in upper Bagmati River Basin in Nepal. Water Science, 31(1):93108. https://doi.org/10.1016/j.wsj.2016.12.001

USDA. 1986. Runoff computation. Hydrology Training Series. Retreived from:

https://www.nrcs.usda.gov/wps/portal/nrcs/detail/national/nedc/?ci $\mathrm{d}=$ stelprdb1047176. Accessed on 12 November 2020.

Van der Vyver, C. 2013. Water poverty index calculation: additive or multiplicative function? Journal of South African Business Research. https://doi.org/10.5171/2013.615770

Vorosmarty, C. J., Green, P., Salisbury, J. and Lammers, R. B. 2000. Global water resources: vulnerability from climate change and population growth. Science 289(5477):284-288. https://doi.org/10.1126/science.289.5477.284

Wescoat, J. L., Headington, L., and Theobald, R. 2007. Water and poverty in the United States. Geoforum 38(5):801-814. https://doi.org/10.1016/j.geoforum.2006.08.007

World Bank. 2010. Agricultural irrigated land, all countries and economics. Retrieved 27 January 2020. https://data.worldbank.org/indicator/AG.LND.IRIG.AG.ZS?fbdid=IwAR3PI9 796fPTRuffYHmRqJN0S1eCafx9IEwm35qAR52ZR9qAF1ZcR9we2nQ

\section{Cite this article as:}

Pathak, L., Pant, R. R., Khadka, U. R., Nepal, J., Poudel, S., Pathak, G. et al. 2020. Spatial analysis of water stress and application of water poverty index in the Mahakali River Basin, Sudurpaschim Province, Nepal. Nepalese Journal of Zoology 4(2):85-94. https://doi.org/10.3126/njz.v4i2.33887 